\title{
Escola Municipal de Música de São Paulo: um exemplo de ensino não formal de música
}

\author{
Sonia Regina Albano de Lima \\ Universidade Estadual Paulista "Júlio de Mesquita Filho"
}

\begin{abstract}
Resumo
O artigo que se segue, primeiramente traça o perfil, a missão pedagógica e os ordenamentos legislativos que regem as escolas de ensino de música formal e não formal para depois se ater mais intensamente na missão institucional e nos objetivos pedagógicos que norteiam a Escola Municipal de Música de São Paulo (EMMSP), que completou 50 anos de criação no ano de 2019. O texto aqui produzido está fundamentado na publicação 50 anos - Escola Municipal de Música de São Paulo (LIMA, 2019) e demais textos desta autora.
\end{abstract}

Palavras-chave: Escolas de música. Ensino formal. Ensino não formal. Ordenamentos. EMM-SP.

O ensino de música no Brasil propagado pelas escolas de ensino formal e não formal de música, atua com diferentes perspectivas pedagógicas, contemplando objetivos pedagógicos variados tanto nos Bacharelados e Licenciaturas em Música, como nos Cursos Técnicos de Ensino Musical e nas Escolas de Ensino de Música não formal' ${ }^{1}$. O artigo aqui descrito traz reflexões sobre a missão pedagógica de cada uma dessas modalidades de ensino, para depois se centrar mais intensamente no ensino de música não formal realizado na Escola Municipal de Música de São Paulo, que no ano de 2019, completou 50 anos de existência.

As escolas de ensino não formal de música, apesar de relevantes social e profissionalmente, não têm merecido o devido apreço das investigações elaboradas pelos pesquisadores, alunos de pós-graduação e professores de música. É grande o número de pesquisas que analisam os processos de ensino e aprendizagem musical fora do espaço escolar, seja em manifestações culturais, em projetos comunitários, em grupos musicais, em programas de rádio ou televisão ou em processos de autoaprendizagem, bem como as

\footnotetext{
${ }^{1}$ Não fazem parte deste artigo o ensino musical realizado em Projetos Culturais, ONGs, instituições religiosas, associações, creches, casas e cursos de apoio ao idoso e aos portadores de necessidades especiais. Também não será palco de análise o salário e o sistema de contratação dos professores, em cada uma das modalidades de ensino contempladas no texto.
} 
investigações sobre o ensino formal de música. Contudo, pouco tem sido relatado acerca da importância das escolas de ensino não formal de música que há anos tem oferecido para a comunidade, um ensino musical voltado para a performance de grande qualidade. A Escola Municipal de Música de São Paulo, com 50 anos de existência; a EMESP Tom Jobim, com 30 anos e a Academia de Música da OSESP, criada em 2006, todas localizadas em São Paulo, são exemplos de escolas de ensino não formal de música preocupadas com a formação profissional de instrumentistas, cantores, cameristas, solistas e regentes.

Começo meu relato descrevendo, de forma sucinta, o que os ordenamentos da atualidade legislam para as escolas de música brasileiras, para depois me ater mais intensamente na missão e nos objetivos que norteiam as escolas de ensino não formal de música, tomando como paradigma, a Escola Municipal de Música de São Paulo, onde fui professora de piano por alguns anos e, em período mais curto, diretora e coordenadora artística. Essa trajetória é que me possibilitou dialogar mais diretamente com essa temática².

Os Bacharelados em Música, conforme dispõe a Resolução CNE/CES nํㅜ 2, de 8 de março de 2004, privilegiam a formação de um profissional com habilidades e aptidões indispensáveis a sua atuação profissional nas dimensões artísticas, culturais, sociais, científicas e tecnológicas, inerentes à área da Música. A sua matriz curricular não contempla disciplinas voltadas para a formação do docente em música. O egresso desse curso, segundo o ordenamento vigente, está capacitado e habilitado para: (a) intervir na sociedade de acordo com suas manifestações culturais, demonstrando sensibilidade e criação artísticas e excelência prática; (b) viabilizar pesquisa científica e tecnológica em Música, visando a criação, compreensão e difusão da cultura e seu desenvolvimento; (c) atuar, de forma significativa, nas manifestações musicais, instituídas ou emergentes; (d) atuar nos diferenciados espaços culturais e, especialmente, em articulação com instituição de ensino específico de Música; (e) estimular criações musicais e sua divulgação como manifestação do potencial artístico.

As Licenciaturas em Música, por sua vez, são reguladas pela Resolução CNE/CP № 1, de 18 de fevereiro de 2002 e acompanham o destino perfilhado pelas demais licenciaturas de outras áreas de conhecimento, atendendo ao que dispõe o art. 62 da LDB no 9394/96, conforme redação dada pela Lei n. 13.415/17. De forma geral, as Licenciaturas Plenas de todas as áreas de conhecimento preveem a formação de docentes em nível superior para atuar na educação básica, bem como a formação mínima para o exercício do magistério na educação infantil e nos cinco primeiros anos do ensino fundamental, oferecida em nível médio,

\footnotetext{
2 Realizei duas publicações comemorativas com relação a esta escola: 50 anos- Escola Municipal de Música de São Paulo (LIMA, 2019); Escola Municipal de Música - 30 anos de ensino profissionalizante (LIMA, 1999), além de minha Tese de Doutorado intitulada Escola Municipal de Música - Criação e Desenvolvimento (LIMA, 1999, PUC-SP).
} 
na modalidade normal. $O$ parágrafo $8^{\circ}$ deste artigo, relata que a matriz curricular desses cursos tomará como referência o ditado pela Base Nacional Comum Curricular (BNCC) ${ }^{3}$, aprovada pelo Conselho Nacional de Educação e homologada no dia 20 de dezembro de 2017 pelo Ministro da Educação. Tanto a Licenciatura como o Bacharelado em Música são considerados cursos superiores de música; de maneira geral, a matriz curricular desses dois cursos agrega disciplinas bem semelhantes destinadas a capacitação de um profissional que vai atuar na área, com exceção das disciplinas pedagógicas e estágio supervisionado oferecidos nas Licenciatura em Música, a fim de que seus egressos possam lecionar na educação básica.

Diferentemente das Licenciaturas e Bacharelados, a Educação Profissional Técnica de Nível Médio não é qualificada como uma formação musical de nível superior, é uma modalidade de ensino de música que permite ao aluno do ensino médio, obter uma certificação profissional para atuar na sociedade como um técnico em música (LIMA, 2003, p. 81-86).

Conforme prevê o parágrafo único do artigo 36-1 da LDB n. 9394/96, incluído pela Lei № 11.741/08, essa modalidade de ensino de natureza formal pode se desenvolver de forma subsequente ao ensino médio, após a sua conclusão, ou concomitantemente ao ensino médio. As instituições que oferecem esse tipo de curso emitem diplomas registrados, com validade nacional, possibilitando ao aluno do ensino médio, prosseguir seus estudos na educação superior. Por vezes, essas escolas também oferecem cursos livres de música não formais, abrigando alunos de diferentes faixas etárias, com data limite para conclusão e um currículo pré-determinado.

Os alunos matriculados nos cursos técnicos na forma concomitante, devem ser alertados que a conclusão do Ensino Médio é condição sine qua non para a obtenção do diploma de técnico em música. Os históricos escolares que acompanham os diplomas e certificados de conclusão nestes cursos, conterão a organização curricular e as competências definidas no perfil profissional de conclusão do curso, no entanto, as disciplinas realizadas nesta modalidade de ensino não podem ser reaproveitadas nos cursos superiores de música, mesmo quando o conteúdo e a carga curricular forem idênticos às disciplinas ofertadas nos cursos superiores de música.

A regulamentação desses cursos está contida na Resolução CNE/CEB n.1, de 05 de dezembro de 2014. Este ordenamento atualiza o Catálogo Nacional de Cursos Técnicos ${ }^{4}$ e

\footnotetext{
${ }^{3}$ Trata-se de um documento de caráter normativo que define o conjunto orgânico e progressivo das aprendizagens essenciais que todos os alunos devem desenvolver ao longo das etapas e modalidades da Educação Básica.

${ }^{4} \mathrm{O}$ Catálogo Nacional de Cursos Técnicos (CNCT) é um instrumento que disciplina a oferta de cursos de educação profissional técnica de nível médio, para orientar as instituições, estudantes e a sociedade em geral. Trata-se de um referencial para subsidiar o planejamento dos cursos e correspondentes qualificações profissionais e
} 
orienta os sistemas de ensino e as instituições públicas e privadas de Educação Profissional e Tecnológica quanto a oferta de cursos técnicos de nível médio, em caráter experimental, de acordo com o previsto no art. 81 da Lei no 9.394/96 (LDB) e nos termos do art. 19 da Resolução CNE/CEB no 6/2012.

Os cursos oferecidos nessa modalidade terão validade máxima de três anos contados da data de ingresso dos alunos e embora privilegiem a preparação de um instrumentista, sua procura ainda é restrita. Neles há uma discrepância entre a formação obtida, a certificação conquistada e as oportunidades de trabalho que esses cursos oferecem (ALMEIDA, 2005).

Eles repassam aos alunos uma formação musical básica. Competências e habilidades mais complexas ao exercício profissional deixam de compor a matriz curricular, dificultando a atuação imediata dos egressos em orquestras, bandas, big bands, conjuntos de câmera, ou mesmo como solistas. Nos concursos públicos esta certificação tem pouca validade, pois a maioria deles exige um profissional graduado em cursos superiores de música ou mesmo em cursos de pós-graduação. Também as disciplinas ofertadas não são passíveis de serem reaproveitadas no ensino superior de música. Como o ingresso nesses cursos só ocorre quando o aluno cursa o ensino médio, o aprendizado de alguns instrumentos é prejudicado no que diz respeito à adequação motora e física do aluno no instrumento em uma idade mais avançada. É sabido, por exemplo, que o aprendizado do violino deve ser iniciado em uma faixa etária bem menor do que a exigida para ingresso nos cursos técnicos de música, a fim de que o aluno possa adquirir maior desenvoltura motora frente ao instrumento. Tanto o início tardio dos alunos no aprendizado musical de alguns instrumentos, quanto a curta duração desses cursos são fatores que prejudicam um pouco a sua procura.

Os Cursos Técnicos de Música levam de 6 a 8 semestres para serem concluídos, devido a sua vinculação com o ensino médio; nesse sentido, um aluno que conclui essa etapa da educação básica, dificilmente vai querer ingressar no curso técnico, ainda que isso seja possível, uma vez que ele poderá ingressar em uma universidade ou faculdade de música, após ser aprovado em teste seletivo, mesmo sem ter um conhecimento musical pleno. Diante deste quadro, podemos afirmar que os cursos técnicos possibilitam a entrada de um aluno mais bem preparado musicalmente nos cursos superiores de música, mas não o capacitam para atuar no mercado de forma plena, o que minimiza sua eficácia.

Os professores que lecionam nesses cursos não necessitam ser graduados em música, eles podem vir de um mercado de trabalho informal, ministrando aulas domiciliares, nas igrejas, nas ONGs ou em eventos diversos; contudo, deve ser dito que o mercado musical atualmente, está cada vez mais preferindo atuar com professores e instrumentistas com

especializações técnicas de nível médio. Em algumas áreas de conhecimento é um curso bastante eficaz, mesmo não sendo considerado um curso superior. 
titulação acadêmica, tanto no Bacharelado quanto na Licenciatura em Música. Trata-se, portanto, de um curso intermediário na formação de um instrumentista, que deve ser complementado com uma graduação. Com o intuito de garantir maior permanência no cenário institucional e obter maior número de alunos, essas escolas também oferecem cursos livres de música sob as mais variadas temáticas.

A Fundação das Artes de São Caetano do Sul é um exemplo de Curso Técnico de Música de excelente qualidade. Seus alunos recebem aulas de instrumentos ou canto, aulas de percepção, harmonia, contraponto, análise, música popular e história da música, com duração de 4 semestres. Os instrumentos ensinados são bateria, clarineta, contrabaixo acústico, contrabaixo elétrico, eufônio, fagote, flauta doce, flauta transversal, guitarra, oboé, percussão popular, percussão erudita, piano clássico, piano popular, saxofone, trombone, trompa, trompete, viola, violão clássico, violão popular, violino e violoncelo. Além das aulas teóricas e de instrumento, a escola oferece aulas de práticas musicais em grupo, entre elas, a participação na Orquestra Sinfônica Jovem, na Orquestra de Violões, no Quarteto de Violões, na Big Band, Camerata de Cordas, Combos, Coro de Repertório, Grupo de Clarinetas, Grupo de Flautas Transversais, Grupo de Flautas Doces, Grupos de Música de Câmara, Grupo de Percussão, Grupo de Trombones, Grupo de Trompas, Grupo de Trompetes, Orquestra de Violões. A escola também promove intercâmbios com organismos artísticos e seus alunos podem participar dos Festivais de Música, entre eles, o Festival de Inverno de Campos do Jordão. O corpo docente desta instituição é composto por profissionais altamente qualificados, muitos deles com formação acadêmica completa (graduação e pósgraduação).

Além do Curso Técnico, esta instituição oferece cursos livres de musicalização, iniciação musical, teatro, artes visuais e ballet para alunos com faixa etária mínima de 12 anos, com ou sem nenhum conhecimento artístico anterior. Esses cursos livres têm duração de seis semestres letivos e se destinam aos alunos de qualquer faixa etária que recebem aulas de instrumento, percepção, rítmica, canto coral, estruturação/harmonia e apreciação musical, história da música e música de câmara. Os alunos do curso livre se quiserem se profissionalizar poderão ingressar no curso técnico, desde que cumpram os quesitos exigidos por lei.

A diferença entre um curso e outro concentra-se: (a) na maior complexidade das disciplinas oferecidas no curso profissionalizante, entre elas, o contraponto, a harmonia, a história da música brasileira, a percepção do repertório tonal e atonal; (b) na faixa etária de ingresso (cursos livres a partir dos 12 anos, curso técnico somente após o ingresso ou a conclusão no ensino médio); (c) no tempo de duração de cada um (6 semestres para os cursos livres e 4 semestres para o curso técnico); (d) na exigência de maior empenho por parte do aluno do curso técnico, tanto na participação das disciplinas como na conclusão da matriz 
curricular (no curso técnico, o aluno deve realizar um recital de 45 minutos e um estágio acompanhado; no curso livre o aluno deve realizar um recital pequeno ao término dos seis semestres).

O aluno do curso livre nesta Fundação só poderá ter aulas em um único instrumento, se optar por outro instrumento deverá se matricular novamente mediante novo processo seletivo. O aluno do curso livre para ingressar no curso técnico além de estar matriculado no ensino médio deverá ter cursado pelo menos um ano do curso livre ou realizar um recital de ingresso.

A ETC de São Paulo e o Conservatório de Tatuí são exemplos de Escolas que também oferecem Cursos Técnicos de Música de excelente qualidade e que, de forma similar, atuam ministrando cursos livres de música. Além deles podemos referendar alguns Conservatórios Musicais que oferecem tanto os cursos técnicos de música como cursos que não são reconhecidos como cursos técnicos.

As escolas de ensino não formal de música são outra modalidade pedagógica de ensino musical, voltadas para a profissionalização de futuros instrumentistas para as orquestras e cantores. Com base no Decreto no. 5.154/04 e a Deliberação CEE 14/97 (Indicação CEE 14/97), os cursos que elas oferecem não necessitam de prévia autorização para funcionamento, nem de posterior reconhecimento do Conselho de Educação competente ${ }^{5}$. Eles podem abrigar alunos sem nenhum conhecimento musical anterior, sem a exigência de ter concluído o ensino médio, como exigido nos Cursos Técnicos de Música. A regulamentação desses cursos é realizada pela própria instituição. Essas têm a liberdade de instituir as disciplinas que serão ministradas, qual a carga horária a ser destinada a cada uma delas, qual a missão institucional que pretendem adotar, bem como o tipo de certificação que será ofertado. Os estudantes dessas escolas de cunho profissionalizante podem optar por receber uma certificação após o cumprimento integral da matriz curricular, ou permanecer na instituição no período que desejarem, a fim de solidificar seus conhecimentos teóricos ou aprimorar sua performance instrumental ou vocal. Essas escolas não dependem de credenciamento institucional e não têm vínculo nem reconhecimento por parte do MEC/CAPES. Seus certificados têm validade legal, porém não podem ser convalidados, validados ou chancelados por escolas oficiais de música ou de outras áreas reconhecidas pelo MEC/CAPES, portanto, as disciplinas e a carga horária a elas destinadas não serão incorporadas ou validadas pelos cursos superiores de música; mesmo assim esses cursos

\footnotetext{
${ }^{5} \mathrm{O}$ ensino profissionalizante não formal acontece em outras áreas de conhecimento; tem duração variável e se destina a proporcionar aos alunos interessados, um apanhado teórico-pragmático voltado para um aprendizado profissional de natureza técnica. Nenhum desses cursos é passível de regulação por parte do Ministério da Educação.
} 
têm acolhido um número significativo de alunos, por vezes, superior ao contingente de estudantes que ingressa anualmente nos cursos de graduação em música e nos cursos técnicos.

Os motivos são variados, os mais relevantes: (a) a matriz curricular desses cursos está focada na produção de saberes musicais e ações necessárias para o desenvolvimento de um profissional que pretende atuar com qualidade e conhecimento suficiente na comunidade musical; (b) os docentes que ministram aulas de instrumento e canto são profissionais que atuam nas orquestras sinfônicas e no meio musical com certa notoriedade; (c) os professores de disciplinas teóricas, na maioria das vezes, são portadores de diploma de graduação em música e com larga experiência docente; (d) esses cursos abrigam alunos com idade inferior à exigida nos cursos técnicos (crianças e jovens), o que permite aos interessados maior tempo na instituição e um aprendizado instrumental mais condizente ao condicionamento físicomotor do aluno no instrumento pretendido; (e) geralmente as escolas que oferecem essa modalidade de ensino são mantidas por instituições governamentais ou fundações que lhes proporcionam melhor infraestrutura e gestão mais duradouro, já que no Brasil, são poucas as instituições privadas que podem arcar com uma infraestrutura bastante dispendiosa, destinada aos cursos de música (LIMA, 2015); (f) essas escolas, mediante processo seletivo, podem receber alunos que apresentam maior aptidão para o aprendizado musical, portanto, permanecem mais tempo na instituição e cumprem sua programação curricular com maior facilidade; (g) as aulas de instrumento e canto são individuais e presenciais, o que permite aos professor adequar seus ensinamentos conforme as necessidades de cada estudante; $(h)$ são diversas as práticas musicais ofertadas nessas escolas, pois comportam professores de instrumentos de todos os naipes, o que nem sempre acontece nas demais escolas de ensino musical, sejam de ensino superior ou técnico; (i) a permanência dos alunos nessas escolas é bastante flexível e sua certificação atende apenas às normas regulamentares instituídas pela instituição; (j) nessas escolas a mesma importância dada ao ensino instrumental é destinada ao ensino teórico-musical.

Como dito anteriormente, na cidade de São Paulo encontramos três escolas de música dessa natureza: a Escola Municipal de Música de São Paulo (EMMSP), a Escola de Música do Estado de São Paulo - EMESP Tom Jobim e a Academia de Música da OSESP. Considerando a minha permanência por algumas décadas na EMMSP enquanto professora de piano e diretora, atenho-me a relatar a missão institucional desta Escola, sua organização curricular e objetivos pedagógicos almejados.

A EMMSP foi criada em fevereiro de 1969, pelo Decreto № 7.984, de 12 de fevereiro de 1969, publicado no Diário Oficial do Município em 13 de fevereiro de 1969, durante a gestão do Prefeito do Município de São Paulo, Brigadeiro José Vicente de Faria Lima, sob a intercessão do Maestro Olivier Toni. Até 2012 ela integrava uma das unidades do 
Departamento do Teatro Municipal de São Paulo da Secretaria de Cultura de São Paulo que comportava quatro divisões, uma delas, a Coordenadoria das Atividades da Iniciação Artística, responsável por gerir esta Escola, a Escola Municipal de Iniciação Artística (EMIA), a Escola Municipal de Bailado, a Orquestra Jovem Municipal até ser extinta e a Orquestra Experimental de Repertório, que encampou a anterior. Hoje é mantida pela Fundação Theatro Municipal de São Paulo da Secretaria Municipal de Cultura, conforme dispõe o Decreto n. 53.225, de 19 de junho de 2012 e artigo 4ํ da Lei 15.380, de 27 de maio de 2011, que relata as atribuições desta Fundação no inciso II, a saber: planejar, desenvolver, promover, incentivar e executar a programação e os demais projetos pertinentes à sua finalidade, assim como as atividades atualmente executadas pelo Departamento Theatro Municipal nos termos da legislação em vigor na data da publicação desta lei, inclusive as relativas aos Conjuntos Artísticos, Unidades Educacionais Profissionalizantes e Corpo Técnico, e as atividades atualmente executadas pela Discoteca Oneyda Alvarenga (grifo nosso).

Sua criação oficial ocorreu no dia 03 de abril de 1969, no antigo Teatro Leopoldo Fróes, à Rua General Jardim, n. 549. Hoje está situada em sede própria situada na Av. São João, n. $281,2^{\circ}$ e $3^{\circ}$ andares. Configura-se como uma escola pública de ensino musical não formal. Com sua criação, a Prefeitura de São Paulo objetivou o ensino de música gratuito a qualquer interessado, possibilitando a futura formação de novos valores artísticos na cidade. Ela nasceu depois de criada a Orquestra Sinfônica Jovem Municipal pelo Decreto n. 7.429, de 03 de abril de 1968, também sob a intercessão do Maestro Olivier Toni. Na ocasião faltavam nas orquestras da capital, instrumentistas de sopro, percussão e cordas. A criação desta orquestra permitiu a muitos jovens desenvolver uma prática orquestral mais intensa. Contudo, faltava uma orientação performática direcionada e contínua, daí o interesse do Maestro Olivier Toni em criar a EMMSP, tanto é que os primeiros alunos da escola pertenciam aos dois organismos.

Graças a esses dois empreendimentos municipais, gradativamente começaram a surgir novas orquestras jovens; aumentaram os instrumentistas nas orquestras sinfônicas brasileiras; os naipes de sopro, percussão e cordas foram gradualmente supridos; outras escolas de ensino não formal de música foram criadas adotando modelo similar de ensino; houve maior interesse dos instrumentistas em seguir seus estudos musicais em cursos superiores de música. Com a criação da ECA-USP, também sob a intercessão e iniciativa do Maestro Olivier Toni, os alunos da EMM poderiam ainda continuar seus estudos musicais gratuitos nessa instituição de ensino superior. Vejamos um depoimento do ex-professor de matérias teóricas, o compositor Osvaldo Lacerda, acerca desse momento:

[...] naquela época estava havendo uma crise na Orquestra Municipal. Aqueles professores mais velhos da Orquestra estavam se aposentando, alguns faleciam, e não havia como renová-los, a não ser que se importassem músicos estrangeiros. $O$ 
Toni, muito corretamente, achou que devia formar profissionais aqui - brasileiros, jovens - e conseguiu convencer o Prefeito de criar a OSJM. Logo depois, ele teria voltado à carga com o Prefeito de São Paulo, dizendo que uma boa orquestra precisaria de uma escola para formar jovens instrumentistas, uma vez que além do estudo no instrumento, teriam de ter um estudo complementar de matérias teóricas, para terem uma formação completa na profissão. Assim foi criada a EMM. (LACERDA, entrevista, p. 134 - LIMA, 2019).

Também em entrevista, o professor de aulas teóricas, professor e mestre em música, Roberto Dante Cavalheiro, revela a importância da EMM no meio artístico-musical:

Quando a escola foi criada, não havia um local onde as pessoas pudessem aprender. Primeiramente nos conservatórios não se ensinava todos os instrumentos, cultuava-se apenas o piano. [...] (hoje) Vamos aos concertos e encontramos nossos ex-alunos tocando. [...] Só de pensarmos que de repente podia se tocar bem certos instrumentos, até então pouco divulgados, como trompa, oboé, trombone! São Paulo não tinha muito bons trompistas [...] Hoje temos excelentes trompistas [...] O que o Gagliardi fez para divulgar este instrumento (trombone)? Veja o trabalho do Fukuda? (violino) [...] As pessoas que trabalhavam na escola implantavam núcleos de formação profissional e estes se expandiam por intermédio de seus alunos para outros locais. Ela teve uma repercussão muito grande. As pessoas que se formam na escola vão constituindo grandes famílias musicais. (CAVALHEIRO, entrevista, p. 110 - LIMA, 2019).

O próprio maestro e compositor Olivier Toni assim se posicionou quanto a criação da Escola Municipal de Música e da ECA-USP:

[...] eu tenho uma preocupação social com a música e, portanto, quero que todos façam música. Com este propósito, apanho o que me aparece no caminho e crio organismos musicais para os outros. [...] Essa ideia de ter a presença da música o mais possível dentro da coletividade foi sempre meu objetivo de vida. As duas escolas são criação minha [...] Na verdade, o meu projeto foi um só, que o aluno fosse na EMM aprender música e em seguida entrasse para a Universidade. Isto é muito lógico, é o que se faz no mundo inteiro. (TONI, entrevista, p. 17 e 21. LIMA, 2019).

Nesses 50 anos de existência pudemos assistir ex-alunos se transformarem em docentes desta mesma instituição, de outras escolas de música e até mesmo de instituições de ensino internacionais; muitos são instrumentistas das Orquestras Sinfônicas Municipal e Estadual, das demais orquestras espalhadas pelo Brasil e das orquestras sinfônicas internacionais que iniciaram seus estudos musicais na EMMSP. A Maestrina Naomi Munakata e Ex-Diretora desta escola, em depoimento, declarou que enquanto aluna desta instituição, estudou violino, canto e harpa. Quase toda a sua formação foi obtida nesta escola e os professores de matérias teóricas contribuíram muito na sua formação. Ela continuou seus estudos no Bacharelado em Composição e Regência e na EMM foi professora de matérias teóricas, chegando a ocupar o cargo de diretora e coordenadora artística. Em entrevista realizada, declarou que a missão institucional da EMM foi preservada mesmo com a criação da EMESP - outra escola de ensino profissionalizante de música não formal; muitos de seus 
alunos têm ingresso garantido nas universidades nacionais e estrangeiras, graças a qualidade de seu ensino. Além das aulas teóricas que ministrou, ela ofereceu cursos de regência esporádicos e regeu, por alguns anos, o Canto Coral da Escola. Ela considera que o grande diferencial dessa escola é propiciar aos estudantes uma formação musical completa, ou seja, matérias teóricas (teoria, harmonia, contraponto, história da música e análise), cursos de instrumento de todos os naipes com os melhores professores da capital e práticas de conjunto variadas. Na verdade, ela tem sido um modelo de ensino de música para outras escolas que foram criadas posteriormente, com a mesma intenção pedagógica.

A EMM cumpre sua missão pedagógica até hoje, de forma sistemática que é a de preparar alunos para atuarem nas orquestras brasileiras. Esta missão inicial foi ampliada gradualmente e hoje ela estendeu seus objetivos para habilitar cantores, coralistas, pianistas, violonistas, cravistas, instrumentistas de orquestra e de música antiga a desenvolverem a carreira solista ou integrar outras formações camerísticas, exercer trabalhos de correpetição ou de acompanhamento musical. Para que esses objetivos sejam cumpridos, seus alunos têm aulas individuais de instrumento ou canto; aulas coletivas de formação teórica e percepção e participam obrigatoriamente, no mínimo por 2 anos, das "práticas de conjunto". O público infantil (dos 9 até os 13 anos), além das aulas de instrumento, recebe aulas teóricas especiais e pode participar da Orquestra Infantojuvenil e do Coral Infantojuvenil, sob a regência de maestros e professores direcionados a lecionarem para esta faixa etária.

A escola oferece aulas de instrumento semanais e individualizadas para flauta transversal, flauta doce, oboé, clarinete, saxofone, fagote, trompa, trompete, trombone, euphonium, tuba, percussão, violão, harpa, piano, cravo, canto lírico, violino, viola, violoncelo e contrabaixo; além das disciplinas teóricas já relatadas e das práticas de conjunto. Essas se dividem entre a participação do aluno na Orquestra Sinfônica Jovem Municipal ${ }^{6}$, no Coro de Adultos e Madrigal, na Orquestra de Cordas, na Banda Sinfônica, ou nas aulas de música de câmara. Também incorporam as práticas de conjunto, grupos camerísticos menores (grupo de saxofone, percussão, camerata de violões, consorte de flauta doce, camerata de violoncelos) e as oficinas de música, entre elas, o Ateliê de Música Contemporânea, o Studio Ópera, as oficinas de canto e cordas barrocas, a oficina de música antiga e a oficina de introdução à fisiologia da voz e a fonética.

Os estudantes ingressam na escola mediante teste seletivo que mede a aptidão do aluno para a música e para o instrumento, a partir dos 9 anos de idade. Esses testes não exigem que o aluno saiba o instrumento ou tenha qualquer conhecimento musical. Nele são

\footnotetext{
${ }^{6}$ A OSJM foi recriada próximo aos anos de 1997, vez que a anterior, criada em 1968 pelo Maestro Olivier Toni e integrada à EMM, foi extinta após a criação da Orquestra Experimental de Repertório. Esta orquestra é composta integralmente com os alunos da EMMSP.
} 
contempladas as habilidades musicais dos candidatos. Vejamos o que relata a Ex-Diretora, Prof. Dr. Marisa Fonterrada, com respeito a implantação desses testes:

\begin{abstract}
Como selecionar quem não tem conhecimento prévio? Porque era uma escola democrática, gratuita, mantida pela Prefeitura, então eu não poderia fazer uma escola só de "geninhos" ou de alunos que tivessem dinheiro para pagar professores particulares, portanto tinham algum conhecimento musical. [...] No meu entender todos deveriam ter acesso. [...] O número de inscritos aumentava ano a ano e aqueles critérios de admissão, os mais surrealistas possíveis, tinham que ser revistos. Um candidato que lia um pouco de música e sabia um pouco de teoria, submetia-se a uma prova de teoria. [...] entretanto, o que fazer com aquela imensa quantidade de sessenta a cem pessoas que se "confessavam" analfabetos musicalmente? Nessa hora é que eu via que os métodos eram surrealistas, porque, realmente, este professor não sabia o que fazer. (FONTERRADA, entrevista, p. 67. LIMA, 2019).
\end{abstract}

Durante anos essa diretora aplicou um texto coletivo de ingresso, criado pelo psicólogo americano Carl Seashore. Era feito com som de laboratório, ele estabelecia apenas uma medida quantitativa, ou seja, discriminar alturas, duração, intensidade, timbre e perceber grupos melódicos e rítmicos. O candidato deveria comparar pares de som e decidir qual o som mais agudo, qual o mais grave, qual o mais curto ou o mais longo. Este teste teve início em 1978 e sofreu inúmeras remodelações no decorrer dos anos. Com ele o rendimento escolar dos ingressantes passou a ser bem melhor.

O processo seletivo desta escola sempre foi problemático, uma vez que anualmente ela recebe um contingente numeroso de candidatos para um número insignificante de vagas ${ }^{7}$. Em 1989, por exemplo, dos 2.736 candidatos inscritos, apenas 564 alunos foram classificados. $\mathrm{Na}$ ocasião não havia infraestrutura e espaço adequados para abrigar maior número de alunos. Mesmo com uma sede nova, a instituição ainda enfrenta o mesmo problema. Hoje ela conta com um total de 840 alunos. O teste Seashore foi sendo modificado nos anos subsequentes devido as dificuldades de aplicação e, em grande medida, concentraram-se basicamente em medir a capacitação dos ingressantes nos instrumentos pleiteados. Vejamos o depoimento do Ex-Diretor Prof. Dr. Henrique Autran Dourado:

Veja o problema da seleção anual. Nós tivemos num determinado ano, 800 candidatos só para piano, é inviável você fazer uma boa escolha escutando 800 candidatos. Tivemos que alterar os critérios seletivos, limitarmos a entrada destes alunos, porque nós não temos vagas para todos. É sabido que um candidato de nove anos de idade que toca alguma coisa, terá muito mais facilidades do que um de 30 que nunca tocou nada. Precisamos saber onde investir, isto é prioritário [...] $\mathrm{Na}$ pior das hipóteses, achei esta limitação positiva. Ela de fato ocorreu nos instrumentos mais concorridos: piano, violão, canto, flauta transversal, clarinete. [...] Como vamos limitar? É complicado limitarmos pela idade, criam-se traumas desnecessários. Chegamos num consenso. A partir de 30 anos, se a pessoa não toca, ela vai ser necessariamente um amador em certos instrumentos. Para estudar

\footnotetext{
7 Um levantamento que realizei no período de 1989 até 1994 para ser apresentado no Congresso Nacional da Federação de Arte-Educadores, comprova que a Escola atendia anualmente uma demanda equivalente a apenas $25 \%$ dos inscritos anuais (LIMA, 2019, p. 232)
} 
contrabaixo é possível que em 8 anos, esta pessoa se torne um profissional [...] Para piano esta prática não funciona, para canto também [...] por exemplo, estudar violino com 30 anos... A mão não tem aquela agilidade exigida pelo instrumento. [...] Para resumir a situação, a partir de 30 anos de idade, o candidato tem obrigatoriamente que tocar duas peças contrastantes. Com isto, evitamos os paraquedistas que realmente não são de forma alguma o motivo de nosso trabalho [...] Os nossos alunos devem sair profissionais de orquestra, nada mais, se quiserem completar seus estudos devem ir para uma faculdade, inclusive com relação as disciplinas teóricas [...] O ideal seria que a Prefeitura tivesse não uma escola de iniciação artística, mas 10 espalhadas em diversos bairros. (DOURADO, entrevista, p. 87-88, LIMA, 2019).

Os Diretores dessa Instituição quase que por unanimidade foram professores ou alunos antigos da Escola que seguiram seus estudos musicais nas Universidades e posteriormente foram nomeados para ocupar esse cargo. O quadro de professores de instrumento é composto, basicamente, por instrumentistas que atuam na Orquestra Sinfônica Municipal e na Orquestra Sinfônica do Estado de São Paulo (OSESP).

Tendo em vista a ligação estreita desta escola com o Theatro Municipal de Música e a Secretaria de Cultura da Municipalidade, muitos artistas internacionais da programação anual do teatro, estendem sua participação, ofertando masterclass e oficinas de música para os alunos desta instituição. Anualmente, a partir de 2014, são realizados os Festivais de Verão com alunos e professores da EMM, oferendo para a comunidade interessada, palestras, cursos, oficinas e recitais comentados gratuitos. A Ópera Studio tem realizado anualmente uma atividade operística de importância capital para os futuros cantores, bem como os demais corpos estáveis agregados a ela.

Os alunos da EMMSP podem ingressar na instituição a partir dos 9 anos de idade e permanecer nela por longos anos. Alunos de faculdade ou de cursos técnicos de música podem ingressar nessa unidade de ensino para complementar seus estudos performáticos e teórico. A regulamentação escolar está inserida em um Manual oferecido ao aluno ingressante, contendo as disciplinas a serem cursadas, os critérios de aprovação e reprovação, os direitos e deveres do corpo discente, além da idade apropriada para receber as aulas no instrumento escolhido, o tempo de duração do curso e as disciplinas que deverão ser cursadas (LIMA, 2019). O aluno poderá obter uma certificação de validade nacional após ter cumprido toda a programação curricular e ter realizado um recital de encerramento em formato de solo, com algum dos corpos estáveis da escola ou com algum grupo de câmera. As disciplinas da matriz curricular contida nos históricos escolares fornecidos aos alunos também não poderão ser revalidadas ou aproveitadas nos cursos superiores de música.

Por algum tempo a EMM difundiu inúmeros projetos artísticos e socioculturais, entre eles, o Projeto "Música nas EMEI - Formação de Monitores Musicais"; "Projeto Humanização nos Hospitais"; Projeto "Saúde ao Meio-Dia" destinado aos servidores da Secretaria Municipal de Saúde, "Palestras para a Terceira Idade", graças a intercessão e empenho do ex-Diretor 
Henrique Autran Dourado e da assistente artística Eliete Brancato. Alunos, professores e corpos estáveis da Escola dirigiam-se aos Hospitais, as EMEls, aos Centros de Saúde da Secretaria Municipal de Saúde e áreas interligadas aos vários setores da Administração Pública Municipal, realizando recitais comentados e audições coletivas com o objetivo de beneficiar a coletividade ali presente com um pouco de música. Também eram realizados no Auditório da Escola e na Biblioteca Maria de Andrade, recitais mensais com a participação de professores e alunos da Escola. Com a saída deste diretor e de sua assistente artística, esses projetos foram sendo gradativamente abandonados. Mesmo assim, ainda são intensas as audições de alunos realizando recitais ou práticas de conjunto contínuas na Sala do Conservatório, agregada ao Praça das Artes (LIMA, 2019).

Durante minha atuação como Diretora e Coordenadora Artística da EMM realizei um questionário padrão para os estudantes desta escola, com o intuito de averiguar o seu perfil, a fim de proporcionar uma participação equânime nas práticas de conjunto ali oferecidas, principalmente as relacionadas à OSJM e OSIJ. Como o questionário não era obrigatório, participaram desta pesquisa apenas 586 alunos, qualificados de acordo com a categoria de instrumento cursado e sua participação nas OSJM e OSIJ. Ela foi realizada na EMM em outubro de 2013, sob minha gestão, com a cooperação do Assistente de Direção Valdemir Aparecido da Silva.

Dos 586 participantes, obtivemos os seguintes resultados: 342 desses alunos estudavam instrumentos sinfônicos na instituição; 248 estudavam outros instrumentos ou canto; apenas 47 alunos participavam da OSIJ e 9 da OSJM. Com esse resultado pude verificar que a participação desses estudantes na OSJM e na OSIJ deveria ser intensificada, já que a missão institucional da Escola era preparar os futuros instrumentistas de orquestra. Contudo, deve ser observado, que os demais participantes realizavam outras práticas de conjunto que não foram medidas quantitativamente na pesquisa. Vejamos os resultados com o contingente percentual atribuído a cada um:

\begin{tabular}{|c|c|c|c|c|c|c|c|c|c|}
\hline $\begin{array}{l}\text { Instrumento } \\
\text { Sinfônico }\end{array}$ & $\%$ & $\begin{array}{c}\text { Outros } \\
\text { Instrumentos }\end{array}$ & $\%$ & $\begin{array}{c}\text { Participa } \\
\text { OSJM }\end{array}$ & $\%$ & $\begin{array}{l}\text { Participa } \\
\text { OSIJ }\end{array}$ & $\%$ & $\begin{array}{l}\text { Participa } \\
\text { OSJM } \\
\text { OSIJ }\end{array}$ & $\%$ \\
\hline 342 & 58,36 & 248 & 42,32 & 48 & 14,04 & 47 & 13,40 & 9 & 2,63 \\
\hline
\end{tabular}

Quadro 1 - Perfil dos Alunos da EMM e participação na OSJM e OSIJ (Valdemir A. Silva e Sonia R. A. de Lima)

Também foi elaborado um segundo quadro contendo a classificação dos alunos de acordo com o naipe estudado e sua participação nas duas orquestras. Os resultados obtidos apontam para um número bem maior de estudantes que participavam dessas orquestras do que o relatado no quadro anterior, o que faz presumir que essas informações poderiam ser 
de alunos que já haviam participados desses dois corpos estáveis em data anterior e atualmente estavam realizando outras práticas de conjunto. Vejamos os resultados auferidos:

\begin{tabular}{|c|c|c|c|c|c|}
\hline Madeiras & № Alunos & Participação OSIJ & Porcentagem & $\begin{array}{l}\text { Participação } \\
\text { OSJM }\end{array}$ & Porcentagem \\
\hline Flauta & 57 & 5 & $8,77 \%$ & 4 & $7,02 \%$ \\
\hline Oboé & 13 & 1 & $7,69 \%$ & 2 & $15,38 \%$ \\
\hline Clarinete & 25 & 3 & $12 \%$ & 3 & $12 \%$ \\
\hline Fagote & 9 & 3 & $33,33 \%$ & 2 & $22,22 \%$ \\
\hline $\begin{array}{c}\text { Metais/ Perc./ } \\
\text { Harpa }\end{array}$ & № Alunos & $\begin{array}{l}\text { Participação } \\
\text { OSIJ }\end{array}$ & Porcentagem & $\begin{array}{l}\text { Participação } \\
\text { OSJM }\end{array}$ & Porcentagem \\
\hline Trompa & 12 & 2 & $16,67 \%$ & 2 & $16,67 \%$ \\
\hline Trompete & 28 & 4 & $14,29 \%$ & 4 & $14,29 \%$ \\
\hline Trombone & 16 & 3 & $18,75 \%$ & 4 & $25 \%$ \\
\hline Eufônio & 2 & 1 & $50 \%$ & 0 & $0 \%$ \\
\hline Tuba & 11 & 1 & $9,09 \%$ & 1 & $9,09 \%$ \\
\hline Percussão & 7 & 3 & $42,86 \%$ & 3 & $42,86 \%$ \\
\hline Harpa & 14 & 1 & $7,14 \%$ & 1 & $7,14 \%$ \\
\hline Cordas & № Alunos & $\begin{array}{l}\text { Participação } \\
\text { OSIJ }\end{array}$ & Porcentagem & $\begin{array}{l}\text { Participação } \\
\text { OSJM }\end{array}$ & Porcentagem \\
\hline Violino & 68 & 14 & $20,59 \%$ & 16 & $23,53 \%$ \\
\hline Viola & 29 & 6 & $20,69 \%$ & 8 & $27,59 \%$ \\
\hline Violoncelo & 28 & 4 & $14,29 \%$ & 6 & $8,70 \%$ \\
\hline Contrabaixo & 23 & 5 & $21,74 \%$ & 2 & $8,70 \%$ \\
\hline
\end{tabular}

Quadro 2 - Perfil dos alunos da EMM de acordo com o naipe estudado e participação na OSJM e OSIJ (Valdemir A. Silva e Sonia R. A. de Lima)

Também foi realizada uma pesquisa com o propósito de saber se os alunos da EMM haviam frequentado ou ainda frequentavam outras instituições de ensino musical, fossem do ensino superior, do ensino técnico ou de cursos de música não formais. Os resultados obtidos são bem frágeis para a realização de uma pesquisa quantitativa, mas de certa maneira trouxeram informações do tipo de aluno que ingressava na escola. Muitos deles frequentavam concomitantemente faculdades e universidades de música, ou eram graduados, alguns vinham de cursos técnicos de música, outros só estudaram música na EMMSP. Algumas crianças, por sua vez, vinham da EMIA - Escola Municipal de Iniciação Artística, a fim de continuarem seus estudos de música ou começaram o seu aprendizado na escola.

Não posso considerar os resultados obtidos como uma fonte segura para a realização de uma pesquisa de natureza quantitativa, mas elas serviram para que eu soubesse o número mais ou menos exato de alunos que tiveram sua formação inicial na escola, quantos estudantes vinham das faculdades e universidades, quantos já eram formados, quantos vinham dos cursos técnicos e quantas crianças que estudaram na EMIA vinham completar seu aprendizado musical na EMMSP. Com essas informações foi possível adotar algumas 
medidas para que mais alunos participassem da OSJM e OSIJ, sem prejudicar as demais práticas de conjunto e medir quais estudantes deveriam ser mais valorizados nos testes de ingresso na escola.

Os relatos até agora narrados neste artigo podem demonstrar a riqueza de atividades musicais desenvolvidas na EMMSP, a infraestrutura que ela comporta, só possível pelo fato de ser mantida por um organismo público, seja ele da Prefeitura, ou da Fundação do Theatro Municipal, além de apontar o número de alunos que recorrem a esta instituição para complementarem ou obterem uma formação musical de nível performático mais intensa.

Essa realidade é motivo para que, cada vez mais, professores e instrumentistas tenham interesse em lecionar nesta instituição, independentemente dos problemas que a cercam e também pelo fato de ela receber anualmente um contingente de alunos bem mais expressivo do que aquele das demais modalidades de ensino musical. $O$ trabalho pedagógico que ela realiza é referência para a sua permanência no ensino musical brasileira a mais de 50 anos. Não cabe a ela outro tipo de ensino que não o de capacitar os jovens para seguirem uma carreira profissional de instrumentistas, cantores, regentes e músicos atuantes. São esses fatores que lhe auferem mérito e sucesso.

Muitos são os caminhos para o aprendizado musical, todos válidos e imprescindíveis; o mais importante para uma instituição é trilhar com competência o caminho pedagógico que ela se propôs a realizar e contar com um quadro docente de nível.

Confesso que não é fácil gerir uma escola dessa natureza, seus diretores têm de ser bastante flexíveis para administrar os interesses da instituição pública que a mantém e fazer cumprir as metas pedagógicas exigidas para a preparação de um instrumentista, além de preservar a extensa programação teórica, instrumental e de conjunto que se intensifica a cada ano. A condução dessa gestão exige um coordenador pedagógico e diretor que tenha conhecimento do funcionamento de uma escola dessa natureza, destinada a preparação performática, que saiba captar o momento exato de alterar seus rumos, suas ações. Aí está sua riqueza. Ela precisa de um gestor muito presente, mais afeito a resolver os problemas que surgem a cada momento do que ocupar um posto de gestão mais estável como aqueles de uma escola formal de ensino superior ou de uma escola técnica de música.

Quando me propus a realizar minha tese de doutorado, a minha proposta de pesquisa era a de que esta escola fosse oficializada (LIMA, 1999, LIMA, 2000), hoje vejo que essa realidade só atrapalharia a vida dessa instituição. Seu maior trunfo é abrigar alunos no tempo necessário para se desenvolverem performaticamente, propiciar a esses jovens o maior número de atividades performáticas que serão futuramente exigidas em suas carreiras, abarcar crianças de 09 anos que poderão permanecer nessa instituição por diversos anos, realizando inúmeras práticas de conjunto, tendo aulas teóricas e recebendo aulas individuais no instrumento escolhido em uma idade propícia para o ensino musical, além de proporcionar 
a esses estudantes um conhecimento teórico que lhes servirá de base durante toda uma vida. Ela tanto abriga alunos do ensino superior, alunos multi-instrumentistas, que desenvolverão no futuro carreiras de solistas, de cameristas, de instrumentistas de orquestra, de compositores, entre outras.

Existem diversas modalidades de ensino de música e professores adequados a cada uma delas. Sem dúvida, a EMMSP é uma das escolas de ensino de música não formal que tem perdurado há muitas décadas e que ainda exerce com qualidade a missão com a qual se propôs trabalhar. Na publicação LIMA, 2019 há vários depoimentos de alunos, professores e diretores que demonstram o apreço que destinam a esta instituição. O compositor Antonio Ribeiro, um dos ex-diretores desta escola assim se posiciona:

[...] sou também agradecido à Escola Municipal de Música por ter sido lá - um espaço nômade, impróprio e insalubre (um dos muitos prédios locados que abrigou a escola) - que recebi grande parte da minha formação musical [...] Temos agora acesso a um conforto e a situações de adequação espacial inéditas e nunca experimentadas [...] saudemos os tempos auspiciosos que virão. (LIMA, 2019, p. 250).

Em sua gestão foram muito os grupos de câmara revitalizados e em cada um dos diretores que ali passaram, percebemos o empenho para preservar a sua missão pedagógica e difundir um estudo performático de qualidade.

Durante esses 50 anos, muitas linhas de ensino de performance surgiram, entre elas, a escola de percussão instituída pelo Prof. Ernesto de Lucca que teve continuidade graças ao empenho da percussionista Elizabeth Del Grande, a escola de trombones do Prof. Gilberto Gagliardi, a técnica de viola instituída pelo Prof. Bela Mori, a escola de contrabaixistas desenvolvida pelo Prof. Sandor Molnar, o aprimoramento da técnica de trompetes iniciada no Brasil com o Prof. Dino Pedini, entre muitas outras, além do trabalho ligado à música antiga iniciado pela Prof. Terezinha Saghaard, pelo Prof. Bernardo Piza e Prof. Marilia Macedo.

Ainda são poucas as publicações que valorizam o trabalho performático ali produzido, mas é inegável que essa escola ao lado de outras escolas de ensino performático não formal, entre elas, a Academia da OSESP e a EMESP ${ }^{8}$, desempenham um excelente serviço na preparação dos futuros instrumentistas e cantores nas mais diversas modalidades, muito em função de atuarem com uma flexibilidade curricular advinda de uma junção entre a prática instrumental e vocal e o ensino teórico da música, por contemplarem no quadro docente, professores de extrema habilidade performática, pelo fato de contarem com uma infraestrutura condizente para essa modalidade de ensino, além de ofertarem práticas de conjunto diversificadas, o que confere aos seus estudantes uma formação adequada para o seu futuro profissional.

\footnotetext{
${ }^{8}$ Essas duas unidades de ensino não serão descritas, devido ao fato de eu nunca ter integrado o quadro de docentes dessas instituições.
} 


\section{Referências}

ALMEIDA, Cristiane Maria Galdino de. Educação musical não-formal e atuação profissional. Revista da Abem, Porto Alegre, v. 13, p. 49-56, set. 2005.

LIMA, Sonia R. Albano de. Os ordenamentos educacionais e sua real aplicabilidade. In: BAPTISTA, Ana Maria Haddad et allium (org). Artes, Ciências e Educação. São Paulo: BT Acadêmica, 2017. p. 151-154.

LIMA, Sonia Regina Albano de. Escola Municipal de Música - Criação e Desenvolvimento. São Paulo: s/n, 1999. Tese (Doutorado) - Pontifícia Universidade Católica de São Paulo. Área de Concentração Comunicação e Semiótica/ARTES. 174 p. e apêndice com a documentação da instituição.

LIMA, Sonia Albano de. Escola Municipal de Música: 30 anos de ensino profissionalizante, São Paulo: Fundação Biblioteca Nacional, 1999, edição autor. 282 p.

LIMA, Sonia Albano de. A educação profissional de música frente à LDB n. 9394/96. Revista da Abem, n. 5, setembro de 2000, p. 39 a 44.

LIMA, Sonia R. Albano de. A resolução CNE/CEB 04/99 e os cursos técnicos de música na cidade de São Paulo. Revista da Abem, n. 8, mar. 2003, p. 81 a 85.

LIMA, Sonia R. Albano de. 50 anos - Escola Municipal de Música de São Paulo. São Paulo: Cartago Editorial, 2019. 298 p.

\section{Legislação Consultada}

BRASIL, Decreto n. 53.225, de 19 de junho de 2010. Aprova o Estatuto da Fundação Theatro Municipal de São Paulo; dispõe sobre o início de funcionamento da Fundação Theatro Municipal de São Paulo e a extinção do departamento Theatro Municipal; regulamenta o artigo 32 da Lei no 15.380 , de 27 de maio de 2011. Disponível em: http://legislacao.prefeitura.sp.gov.br/leis/decreto-53225-de-19de-junho-de-2012. Acesso em: dez. 2019.

BRASIL, Decreto n. 7.429, de 03 de abril de 1968. Dispõe sobre a criação de Orquestra Sinfônica Jovem Municipal e dá outras providências. Disponível em: https://leismunicipais.com.br/a/sp/s/saopaulo/decreto/1968/742/7429/decreto-n-7429-1968. Acesso em: dez. 2019.

BRASIL, Decreto o 5.154, de 23 de julho de 2004. Regulamenta o $\S 2^{\circ}$ do art. 36 e os arts. 39 a 41 da Lei n. 9394, de 20 de dezembro de 1996, que estabelece as diretrizes e bases da educação nacional, e dá outras providências. Disponível em: http://www.planalto.gov.br/ccivil_03/_ato20042006/2004/decreto/d5154.htm. Acesso em: dez. 2019.

BRASIL, Decreto no 7.984, de 12 de fevereiro de 1969, publicado no D.O.M. em 13 de fevereiro de 1969. Dispõe sobre a criação da Escola Municipal de Música e dá outras providências. Disponível em: https://leismunicipais.com.br/a/sp/s/sao-paulo/decreto/1969/799/7984/decreto-n-7984-1969. Acesso em: dez. 2019.

BRASIL, Deliberação CEE 14, de $01^{\circ}$ de outubro de 1997. Fixa diretrizes para a educação profissional no sistema de ensino do Estado de São Paulo, acesso em dezembro de 2019. Disponível em: http://siau.edunet.sp.gov.br//temLise/arquivos/notas/delcee14_97.htm. Acesso em: dez. 2019.

BRASIL, LDB n. 9394, de 20 de dezembro de 1996 (atualizada). Estabelece as diretrizes e bases da educação. Disponível em: http://www.planalto.gov.br/ccivil_03/leis/19394.htm. Acesso em: dez. 2019.

BRASIL, Lei n. 15.380, de 27 de maio de 2011. Autoriza o Poder Executivo a instituir a Fundação Theatro Municipal de São Paulo; cria cargos de provimento efetivo e em comissão; extingue o departamento Theatro Municipal; absorve as gratificações que especifica na Escala de Vencimentos do Quadro de Atividades Artísticas; dispõe sobre o afastamento de servidores da Administração Direta; altera 0 art. $1^{\circ}$ da Lei ํㅜㄴ 14.132, de 24 de janeiro de 2006, e dá providências correlatas. 
Disponível em: http://legislacao.prefeitura.sp.gov.br/leis/lei-15380-de-27-de-maio-de-2011. Acesso em: dez. 2019.

BRASIL, Lei oㅜ 11.741, de 16 de julho de 2008. Altera dispositivos da Lei n. 9394/96, que estabelece as diretrizes e bases da educação nacional, para redimensionar, institucionalizar e integrar as ações da educação profissional técnica de nível médio, da educação de jovens e adultos e da educação profissional e tecnológica. Disponível em: http://www.planalto.gov.br/ccivil_03/_Ato20072010/2008/Lei/L11741.htm. Acesso em: dez. 2019.

BRASIL, Resolução CNE/CEB n.1, de 05 de dezembro de 2014. Atualiza e define novos critérios para a composição do Catálogo Nacional de Cursos Técnicos, disciplinando e orientando os sistemas de ensino e as instituições públicas e privadas de Educação Profissional e Tecnológica quanto à oferta de cursos técnicos de nível médio em caráter experimental, observando o disposto no art. 81 da Lei no 9.394/96 (LDB) e nos termos do art. 19 da Resolução CNE/CEB no 6/2012. Disponível em: http://portal.mec.gov.br/index.php?option=com_docman\&view=download\&alias=16705-res1-2014cne-ceb-05122014\&category_slug=dezembro-2014-pdf\&lte. Acesso em: dez. 2019.

BRASIL, Resolução CNE/CES no 2, de 8 de março de 2004. Aprova as Diretrizes Curriculares Nacionais do Curso de Graduação em Música e dá outras providências. Disponível em: http://portal.mec.gov.br/cne/arquivos/pdf/CES02-04.pdf. Acesso em: dez. 2019.

BRASIL, Resolução CNE/CP n. 1, de 18 de fevereiro de 2002. Institui Diretrizes Curriculares Nacionais para a Formação de Professores da Educação Básica, em nível superior, curso de licenciatura, de graduação plena. Disponível em:

http://portal.mec.gov.br/seesp/arquivos/pdf/res1_2.pdf. Acesso em: dez. 2019. 